\section{Health priorities gain patent reprieve for developing countries}

Michael Cherry

In an unexpected move, the World Trade Organization (WTO) last week agreed that patent laws would not be used to prevent developing countries from using generic medicines to protect public health.

The trade-related aspects of intellectual property (TRIPS) agreement currently permits countries to license the production of cheaper copies of patented drugs where this is necessary on publichealth grounds. But if the WTO had required all its members to recognize patents by 2006 , as was originally planned, these rights could have fallen away.

The declaration agreed at the WTO meeting in Doha, Qatar, on 14 November postpones this deadline to 2016 for leastdeveloped countries, and states that the agreement should be implemented in a manner that is "supportive of WTO members' right to protect public health, and in particular to promote access to medicines for all". The agreement was brokered by Brazil — which produces large quantities of generic drugs - and was unexpectedly backed by the United States in the face of opposition from the US pharmaceutical industry.

In addition, individual countries will be free to determine the circumstances under which licences to manufacture generics are issued. The Doha declaration acknowledges that these are not confined to emergency situations - but if countries declare an emergency they can issue compulsory licences without prior negotiation with the patent owner.

The loosely worded TRIPS agreement has been open to different interpretations in the past, leading to threats of trade sanctions and legal actions of the kind that the South African Pharmaceutical Manufacturers Association brought against its government earlier this year for enacting legislation which it claimed threatened intellectual property rights (see Nature 410, 1013; 2001). Mark Heywood, national secretary of South Africa's Treatment Action Campaign, hails the new agreement as "a step in the right direction" that should prevent such actions in future.

"Doha sends a strong message that people's health overrides the interests of big drug companies," agrees Michael Bailey, senior policy adviser to the charity Oxfam. But problems will remain for countries that lack a generic drugs industry, and therefore cannot obtain drugs by issuing a compulsory licence.

\title{
Cycle studies see carbon sinks rise to prominence
}

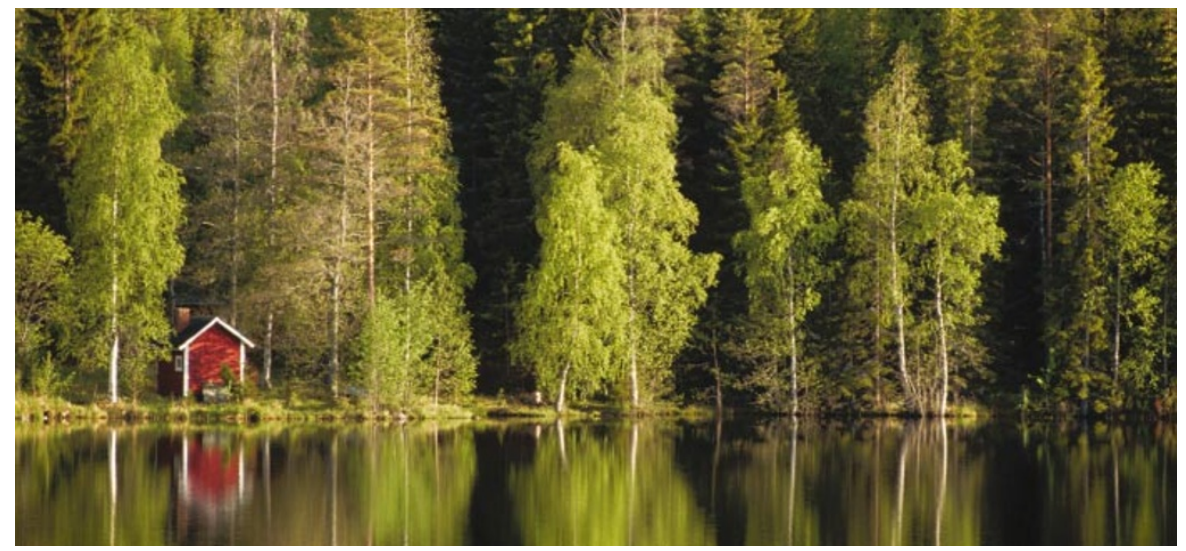

Green schemes: two studies will look at how planting forests could reduce atmospheric carbon.

\section{Quirin Schiermeier}

As the dust settles on the latest round of negotiations over the Kyoto Protocol on climate change, researchers are turning their attention to one of the most controversial scientific issues behind the accord - the role of sinks such as soils and vegetation in absorbing atmospheric carbon.

Two ambitious studies - one in Europe, the other in the United States - are set to assess how much carbon is absorbed by such sinks. CarboEurope, a cluster of eight related projects, was established last year with the aim of understanding and quantifying the exchange of carbon between vegetation and the atmosphere. A similar programme was proposed last week by the US Carbon Cycle Interagency Working Group, a committee that includes representatives of the major US funding organizations. Both studies are aimed at laying the groundwork for better monitoring networks to verify the protocol once it comes into force.

Carbon sinks are an important component of the Kyoto Protocol. About half of the 6.5 billion tonnes of carbon emitted globally by burning fossil fuels is taken up by vegetation and stored as organic matter. According to the Kyoto rules, the details of which were negotiated earlier this month in Marrakech (see Nature 414, 238; 2001), countries receive credits for carrying out activities that increase the absorption of carbon, such as planting forests. The credits can be used to reduce the amount by which they have to cut their emissions, or can be traded on the global emissions market.

But the protocol is vague about how credits for sink activities will be assessed. Governments currently use data from forest inventories, which measure forest areas and timber volume, to determine the effects of sinks. Alternative techniques, such as measuring atmospheric carbon levels, pro- duce different estimates of sink potential, leaving the process open to manipulation by governments keen to earn credits.

"From a scientific point of view, only a full continental carbon balance can avoid unwanted loopholes," says Ernst-Detlef Schulze, managing director of the Max Planck Institute for Biogeochemistry in Jena, and one of the initiators of CarboEurope.

CarboEurope, which receives 30 million euros (US\$26 million) from the European Commission and national governments, involves around 400 scientists from 75 European institutes. Data from various sources, including soil samples, forest inventories and plant respiration studies, are being made available in consistent formats to cross-check the results of different model calculations of carbon cycles. The programme is expanding the number of observations with the aim of establishing a full monitoring system by 2006 .

CarboEurope will also monitor the reaction of sinks to climate change. Many researchers fear that the entire European carbon sink could be saturated by 2050 and eventually become a net emitter of carbon.

Congress is due to decide on funding for the US project, known as the North American Carbon Program, before the end of the year. If funding is secured, work will start next year to establish a monitoring network by 2008 .

With policy decisions resting on the results of the two studies, some researchers think that European and US carbon research should be linked more closely. "It would be politically very unwise if carbon research programmes developed continental biases too much," says Han Dolman, a meteorologist at the Wageningen University and Research Centre in the Netherlands and chairman of the CarboEurope steering committee.

http://www.bgc-jena.mpg.de/public/carboeur 